\title{
Synergistic Ion-pair Extraction and Separation of Trivalent Lanthanoid Ions with 4-Isopropyltropolone and 1,10-Phenanthroline into o-Dichlorobenzene
}

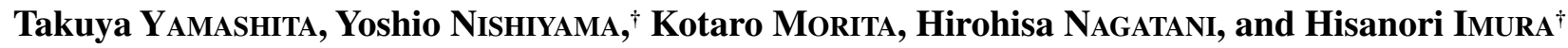 \\ Division of Material Chemistry, Graduate School of Natural Science and Technology, Kanazawa University, \\ Kakuma, Kanazawa 920-1192, Japan
}

\begin{abstract}
The synergistic extraction of trivalent lanthanoid ( $\operatorname{Ln}(\mathrm{III})$ ) ions with 4-isopropyltropolone (Hipt) and 1,10-phenanthroline (phen) in $o$-dichrolobenzene (DCB) was investigated. The synergistic effect in DCB is more significant than that in toluene, and the polynuclear complexes found in toluene are not formed in DCB. Based on the 3-dimensional equilibrium analysis, the extracted species for $\mathrm{La}(\mathrm{III}), \mathrm{Eu}(\mathrm{III})$, and $\mathrm{Lu}(\mathrm{III})$ are found to be ion-pairs, such as $\mathrm{Ln}(\mathrm{ipt})_{2} \mathrm{phen} \cdot \mathrm{ClO}_{4}$ and $\mathrm{Ln}$ (ipt) $)_{2}$ (phen) $\cdot \mathrm{ClO}_{4}$ in the presence of $\mathrm{NaClO}_{4}$ as a salt, and the extraction constants of the respective species were determined. The simultaneous extraction of different lanthanoids in the present extraction system was demonstrated. The separation factors between lighter lanthanoids were larger than those with 2-ethylhexyl phosphonic acid mono-2ethylhexyl ester, an excellent extractant for the separation of lanthanoid ions, in decane.
\end{abstract}

Keywords Lanthanoid, 4-isopropyltropolone, 1,10-phenanthroline, synergistic extraction

(Received October 19, 2019; Accepted December 10, 2019; Advance Publication Released Online by J-STAGE December 20, 2019)

\section{Introduction}

The synergistic extraction of trivalent lanthanoid $(\operatorname{Ln}(\mathrm{III}))$ ions has been investigated extensively with the co-use of acidic chelating extractants, such as $\beta$-diketones, ${ }^{1-10} \quad 8$-quinolinol derivatives, ${ }^{11-13}$ and tropolone derivatives, ${ }^{14,15}$ and neutral ligands, such as tributylphosphate, ${ }^{1,2}$ trioctylphosphine oxide, ${ }^{1,10,15}$ crown ethers, ${ }^{7,8}$ and 1,10-phenanthroline (phen) derivatives., ${ }^{3,6,14}$ The synergistic effect is explained by the adduct complex formation of metal chelates with neutral ligands in the extraction phase, allowing for the displacement of coordinated water molecules in Ln(III) species extracted with the chelating agent alone. Thus, the synergistic enhancement of the extractability of $\operatorname{Ln}$ (III) was widely reported for various combinations of above-mentioned chelating agents and neutral ligands. On the other hand, since the extraction enhancement occurs across the Ln(III) series, there are reported to be limited synergistic extraction systems that improve the separation efficiency between different lanthanoids, ${ }^{3-6}$ such as the one with 2-thenoyltrifluoroacetone and phen.

We demonstrated a superior synergistic effect on heavier $\mathrm{Ln}$ (III) with the co-use of 4-isopropyltropolone (Hipt) and phen in toluene, ${ }^{14}$ making this extraction system a promising candidate for a superior separation of lanthanoids. Hipt alone extracts $\mathrm{Ln}(\mathrm{III})$ in the form as the polynuclear metal complexes, ${ }^{16,17}$ which are disadvantageous to the extraction separation of different lanthanoids because these lanthanoids are co-extracted

† To whom correspondence should be addressed.

E-mail: yosi1166@se.kanazawa-u.ac.jp (Y. N.); imura@staff. kanazawa-u.ac.jp (H. I.) via formation of heteropolynuclear complexes containing them. On the other hand, the presence of phen as a synergist inhibits the formation of such polynuclear complexes substantially, but not completely by adduct complex formation. ${ }^{14}$

In the present study, the synergistic extraction of $\mathrm{Ln}$ (III) with Hipt and phen was investigated in $o$-dichlorobenzene (DCB), which has a higher dielectric constant than toluene, and thus is promising as an extraction diluent to inhibit the formation of polynuclear complexes. ${ }^{17}$ As a result of an equilibrium analysis of the extraction data, it was found that the Ln(III) species are extracted not as polynuclear complexes, but as ion pair in the presence of $\mathrm{ClO}_{4}{ }^{-}$into the $\mathrm{DCB}$ phase. The separation factors between different lanthanoids in the present extraction system was also examined by the simultaneous extraction of all $\mathrm{Ln}$ (III) ions, except for Pm(III).

\section{Experimental}

\section{Reagents and chemicals}

Hipt (TCI, guaranteed reagent grade) was used without further purification. Phen (Ishizu, guaranteed reagent grade) was used as an anhydrate after recrystallization using benzene. All other chemicals were of analytical or guaranteed reagent grade, and used without further purification. Deionized water (18.2 M $\Omega$ ) provided with a Milli-Q equipment (Millipore, Gradient A10) was used throughout.

\section{Apparatus}

A reciprocal shaker (TAITEC, SR-2) was used for agitation of the aqueous and organic phases. A pH meter (HORIBA, F-52) equipped with a micro glass combined electrode (HORIBA, 
9678-10D) was calibrated with standard $\mathrm{pH}$ buffer solutions. An inductively coupled plasma mass spectrometer (ICP-MS, Seiko Instruments SPQ 8000) or a polarized Zeeman graphite furnace atomic absorption spectrophotometer (GFAAS, Hitachi, $\mathrm{Z}-8270$ ) was used for the determination of $\operatorname{Ln}(\mathrm{III})$ in aqueous solutions. A UV/Vis spectrophotometer (JASCO, V-570) was used for the determination of Hipt and phen in the aqueous and organic phases. An electrospray ionization time-of-flight mass spectrometer (MICROMASS, micromass LCT or JEOL, JMS-T100 TD) was used for identification of the Ln(III) species extracted to the organic phase.

\section{Extraction procedure}

An aliquot $\left(5.0 \mathrm{~cm}^{3}\right)$ of an aqueous phase containing $1.0 \times$ $10^{-6}-1.0 \times 10^{-4} \mathrm{~mol} \mathrm{dm}^{-3}$ (typically $1.0 \times 10^{-5} \mathrm{~mol} \mathrm{dm}^{-3}$ ) $\mathrm{Ln}(\mathrm{III})$, $1.0 \times 10^{-1} \mathrm{~mol} \mathrm{dm}^{-3} \mathrm{NaCl}$ or $\mathrm{NaClO}_{4}$, and $1.0 \times 10^{-3} \mathrm{~mol} \mathrm{dm}^{-3}$ $\mathrm{pH}$ buffers (monochloroacetic acid, acetic acid, MES) and an aliquot $\left(5.0 \mathrm{~cm}^{3}\right)$ of an organic phase containing $2.5 \times 10^{-5}$ $5.0 \times 10^{-3} \mathrm{~mol} \mathrm{dm}^{-3}$ Hipt and $1.0 \times 10^{-5}-1.0 \times 10^{-2} \mathrm{~mol} \mathrm{dm}^{-3}$ phen were shaken mechanically for $1 \mathrm{~h}$ at $25^{\circ} \mathrm{C}$. After two phases were separated by centrifugation, the $\mathrm{pH}$ value in the aqueous phase was measured. The metal concentration in the aqueous and the organic phase (after back-extraction into an equal volume of $0.1 \mathrm{~mol} \mathrm{dm}^{-3}$ nitric acid solution by shaking for $1 \mathrm{~h}$ ) was determined by GFAAS or ICP-MS. The distribution ratio $(D)$ was calculated from the concentrations of $\operatorname{Ln}(\mathrm{III})$ in both phases. In the case of the simultaneous extraction of all $\mathrm{Ln}$ (III) ions, except for $\mathrm{Pm}(\mathrm{III})$, the concentrations of $\mathrm{Ln}$ (III) ions were reduced to $1.0 \times 10^{-6} \mathrm{~mol} \mathrm{dm}^{-3}$ so that excess amounts of Hipt and phen over $\operatorname{Ln}(\mathrm{III})$ were contained in the solution.

To determine the distribution constant of Hipt, an aliquot $\left(5.0 \mathrm{~cm}^{3}\right)$ of the organic (DCB) phase containing $1.0 \times 10^{-2} \mathrm{~mol} \mathrm{dm}^{-3}$ Hipt and an aliquot $\left(5.0 \mathrm{~cm}^{3}\right)$ of the aqueous phase containing $1.0 \times 10^{-1} \mathrm{~mol} \mathrm{dm}^{-3} \mathrm{NaClO}_{4}$ and $\mathrm{pH}$ buffers $\left(1.0 \times 10^{-3} \mathrm{~mol} \mathrm{dm}^{-3}\right.$ acetic acid, $1.0 \times 10^{-3} \mathrm{~mol} \mathrm{dm}^{-3}$ MES, $7.1 \times 10^{-3} \mathrm{~mol} \mathrm{dm}^{-3}$ MOPS, or $5.6 \times 10^{-3} \mathrm{~mol} \mathrm{dm}^{-3}$ TAPS) were shaken mechanically for $1 \mathrm{~h}$ at $25^{\circ} \mathrm{C}$. The $\mathrm{pH}$ value of the aqueous phase was adjusted to $2-9$ with $1.0 \times 10^{-1} \mathrm{~mol} \mathrm{dm}^{-3} \mathrm{HCl}$ and $1.0 \times 10^{-1} \mathrm{~mol} \mathrm{dm}^{-3} \mathrm{NaOH}$. After the two phases were separated by centrifugation, the $\mathrm{pH}$ value of the aqueous phase was measured. An aliquot of the aqueous phase was diluted to be a solution containing $1.0 \times 10^{-1} \mathrm{~mol} \mathrm{dm}^{-3} \mathrm{NaOH}$ and $1.0 \times 10^{-1}$ mol dm ${ }^{-3} \mathrm{NaCl}$ in which Hipt was completely dissociated. Then the absorbance of ipt $^{-}$in the solution was measured at $387 \mathrm{~nm}$. The concentration of the total Hipt in the aqueous phase was determined from the absorbance measured and the molar absorptivity of ipt determined separately as $1.16 \times 10^{4} \mathrm{dm}^{3} \mathrm{~mol}^{-1} \mathrm{~cm}^{-1}$. Hipt in the organic phase was back-extracted with $0.1 \mathrm{~mol} \mathrm{dm}^{-3}$ $\mathrm{NaOH}$, and the concentration was determined in the same manner as that in the aqueous phase. The distribution ratio of Hipt was calculated according to the following equation:

$$
D_{\text {Hipt }}=\frac{c_{\text {Hipt,org }}}{c_{\text {Hipt,aq }}},
$$

where $c_{\text {Hipt,org }}$ and $c_{\text {Hipt,aq }}$ are the total concentrations of Hipt in the organic and aqueous phases, respectively.

To determine the distribution constant of phen, an aliquot $\left(5.0 \mathrm{~cm}^{3}\right)$ of the DCB phase containing $1.0 \times 10^{-3} \mathrm{~mol} \mathrm{dm}^{-3}$ phen and an aliquot $\left(5.0 \mathrm{~cm}^{3}\right)$ of the aqueous phase containing $1.0 \times 10^{-1} \mathrm{~mol} \mathrm{dm}^{-3} \mathrm{NaCl}$ or $\mathrm{NaClO}_{4}$ and $1.0 \times 10^{-3} \mathrm{~mol} \mathrm{dm}^{-3}$ $\mathrm{pH}$ buffers (monochloroacetic acid, acetic acid, MES, or MOPS) were shaken mechanically for $1 \mathrm{~h}$ at $25^{\circ} \mathrm{C}$. The $\mathrm{pH}$ value of the aqueous phase was adjusted to $1-8$ with $1.0 \times 10^{-1} \mathrm{~mol} \mathrm{dm}^{-3}$ $\mathrm{HCl}$ and $1.0 \times 10^{-1} \mathrm{~mol} \mathrm{dm}^{-3} \mathrm{NaOH}$. After centrifugation, the
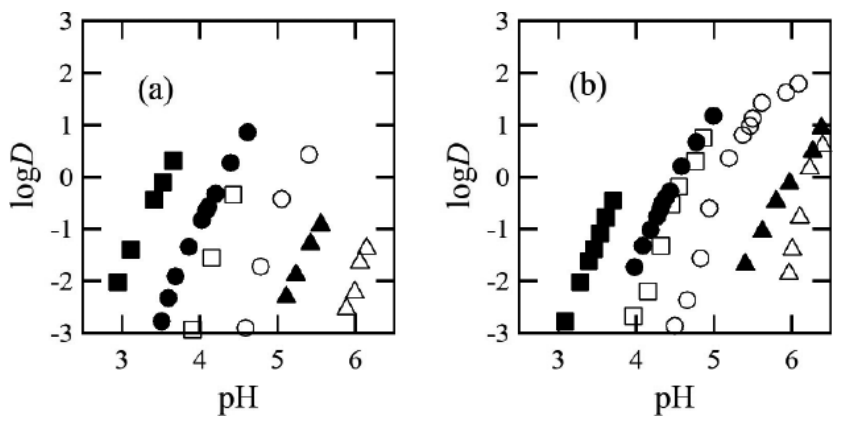

Fig. 1 Distribution ratio of $\mathrm{La}(\mathrm{III})(\triangle, \mathbf{\Delta}), \mathrm{Eu}(\mathrm{III})(\bigcirc, \boldsymbol{\bullet})$ and $\mathrm{Lu}(\mathrm{III})$ $(\square, \boldsymbol{\square})$ with Hipt in the presence (closed symbols) or absence (opened symbols) of phen. DCB and toluene are used as extraction solvents in panels (a) and (b), respectively. The initial concentrations of $\operatorname{Ln}(\mathrm{III})$, Hipt, phen, and $\mathrm{NaCl}\left(\mathrm{NaClO}_{4}\right.$ only in the case of using Hipt alone in DCB) are $1.0 \times 10^{-5} \mathrm{~mol} \mathrm{dm}^{-3}, 1.0 \times 10^{-3} \mathrm{~mol} \mathrm{dm}^{-3}, 1.0 \times 10^{-3} \mathrm{~mol} \mathrm{dm}^{-3}$, $1.0 \times 10^{-1} \mathrm{~mol} \mathrm{dm}^{-3}$, respectively.

$\mathrm{pH}$ value of the aqueous phase was measured. An aliquot of the aqueous phase was diluted to be a solution containing $1.0 \times 10^{-1}$ mol dm ${ }^{-3}$ sulfuric acid to form Hphen ${ }^{+}$completely. Then, the absorbance of Hphen ${ }^{+}$in the solution was measured at $271 \mathrm{~nm}$. The concentration of total phen in the aqueous phase was determined from the absorbance measured and the molar absorptivity of Hphen ${ }^{+}$determined separately as $3.02 \times 10^{4} \mathrm{dm}^{3}$ $\mathrm{mol}^{-1} \mathrm{~cm}^{-1}$. Phen in the organic phase was back-extracted with $0.1 \mathrm{~mol} \mathrm{dm}^{-3}$ sulfuric acid, and the concentration was determined in the same manner as that in the aqueous phase. The distribution ratio of phen was calculated according to the following equation:

$$
D_{\text {phen }}=\frac{c_{\text {phen,org }}}{c_{\text {phen,aq }}},
$$

where $c_{\text {phen,org }}$ and $c_{\text {phen,aq }}$ are the total concentrations of phen in the organic and aqueous phases, respectively.

\section{Results and Discussion}

\section{The extraction behavior of Ln(III) with Hipt and phen}

Figure 1 shows the logarithmic distribution ratio $(\log D)$ of $\mathrm{Ln}$ (III) with Hipt in the presence or absence of phen in DCB and toluene as a function of the $\mathrm{pH}$ in the aqueous phase. The $\log D$ was found to be enhanced in the presence of phen, and the enhancement is more significant in DCB. As shown in Fig. S1 (Supporting Information), the $\log D$ of $\operatorname{Ln}(\mathrm{III})$ in DCB is independent of the metal concentration, indicating that $\mathrm{Ln}(\mathrm{III})$ is extracted as a mononuclear metal complex. Furthermore, the synergistic extraction behavior in DCB is found to depend on the type of salts used, i.e. the extractability with $\mathrm{NaClO}_{4}$ being higher than that with $\mathrm{NaCl}$ (Fig. 2), suggesting that $\mathrm{ClO}_{4}{ }^{-}$is involved with the extraction of $\operatorname{Ln}(\mathrm{III})$, e.g. $\mathrm{Ln}(\mathrm{III})$ species is extracted into $\mathrm{DCB}$ as an ion pair with $\mathrm{ClO}_{4}^{-}$. In the following, we analyzed the extraction behavior of $\mathrm{Ln}(\mathrm{III})$ in the synergistic extraction system with Hipt, phen, and $\mathrm{ClO}_{4}^{-}$in DCB (Hiptphen- $\mathrm{ClO}_{4}^{-}$-DCB system) based on the extraction equilibrium. For that purpose, we also elucidated the distribution behavior of Hipt and phen in DCB in the presence of $\mathrm{ClO}_{4}^{-}$.

\section{Determination of distribution constant of Hipt in DCB}

Figure 3 shows the distribution ratio $\left(D_{\text {Hipt }}\right)$ of Hipt between the aqueous and DCB phases as a function of the $\mathrm{pH}$. 


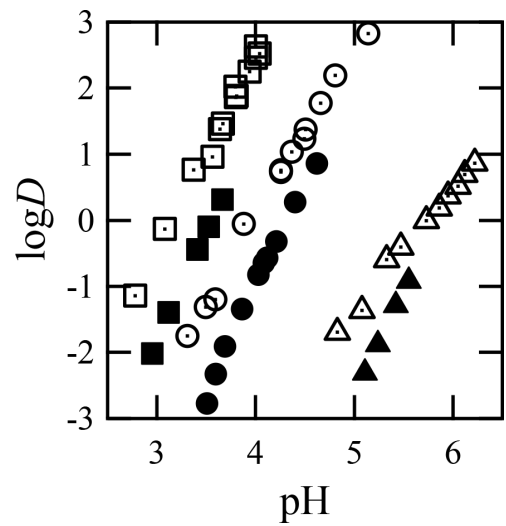

Fig. 2 Salt effect of the distribution ratio of $\mathrm{La}(\mathrm{III})(\Delta, \mathbf{\Delta}), \mathrm{Eu}(\mathrm{III})$ $(\odot, \bullet)$, and Lu(III) $(\odot, \boldsymbol{\square})$ with Hipt and phen in DCB. $1.0 \times 10^{-1} \mathrm{~mol}$ $\mathrm{dm}^{-3} \mathrm{NaCl}(\boldsymbol{\Lambda}, \bullet, \square)$ or $1.0 \times 10^{-1} \mathrm{~mol} \mathrm{dm}^{-3} \mathrm{NaClO}_{4}(\triangle, \odot, \square)$ was used as a salt. The initial concentrations of $\operatorname{Ln}(\mathrm{III})$, Hipt, and phen are $1.0 \times 10^{-5} \mathrm{~mol} \mathrm{dm}^{-3}, 1.0 \times 10^{-3} \mathrm{~mol} \mathrm{dm}^{-3}, 1.0 \times 10^{-3} \mathrm{~mol} \mathrm{dm}^{-3}$, respectively.

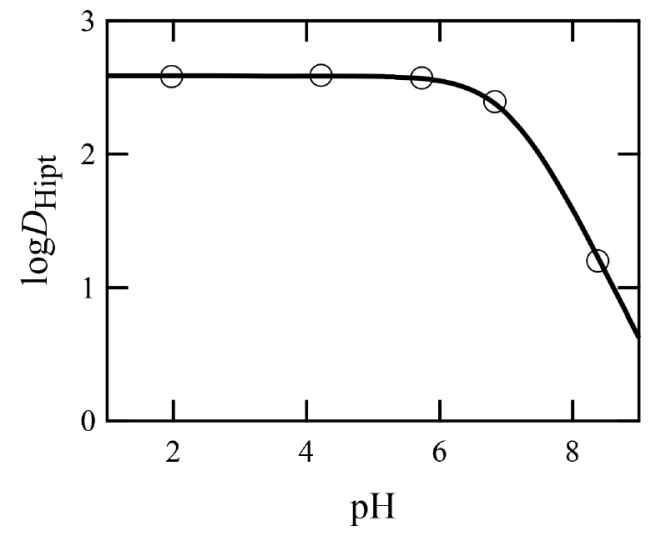

Fig. 3 Distribution ratio of Hipt as a function of $\mathrm{pH}$ in the aqueous phase. $1.0 \times 10^{-1} \mathrm{~mol} \mathrm{dm}^{-3} \mathrm{NaClO}_{4}$ is used as a salt. The initial concentration of Hipt is $1.0 \times 10^{-2} \mathrm{~mol} \mathrm{dm}^{-3}$. The solid curve shows the calculated values.

The distribution curve shows a typical distribution profile for a monobasic acid, i.e. at lower $\mathrm{pH}$ region where the neutral Hipt is dominant, $\log D_{\text {Hipt }}$ is almost constant, while $\log D_{\text {Hipt }}$ follows a straight line having a slope of -1 at higher $\mathrm{pH}$ region where anionic ipt $^{-}$is dominant. The experimentally determined $D_{\text {Hipt }}$ value is expressed as follows:

$$
D_{\text {Hipt }}=\frac{K_{\text {D,Hipt }}}{1+\left(K_{\text {a,Hipt }} /\left[\mathrm{H}^{+}\right]\right)}
$$

where the distribution constant $\left(D_{\text {Hipt }}\right)$ and the acid dissociation constant $\left(K_{\mathrm{a}, \text { Hipt }}\right)$ of Hipt are defined by

$$
\begin{aligned}
& K_{\mathrm{D}, \text { Hipt }}=\frac{[\mathrm{Hipt}]_{\text {org }}}{[\text { Hipt }]}, \\
& K_{\text {a,Hipt }}=\frac{\left[\mathrm{ipt}^{-}\right]\left[\mathrm{H}^{+}\right]}{[\text {Hipt }]} .
\end{aligned}
$$

By fitting the $\log D_{\text {Hipt }}$ curve in Fig. 3 by a nonlinear leastsquares method based on Eq. (3), the values of $\log K_{\text {D,Hipt }}$ and $\mathrm{p} K_{\mathrm{a}, \text { Hipt }}$ were determined to be $2.59 \pm 0.01$ and $7.04 \pm 0.02$,

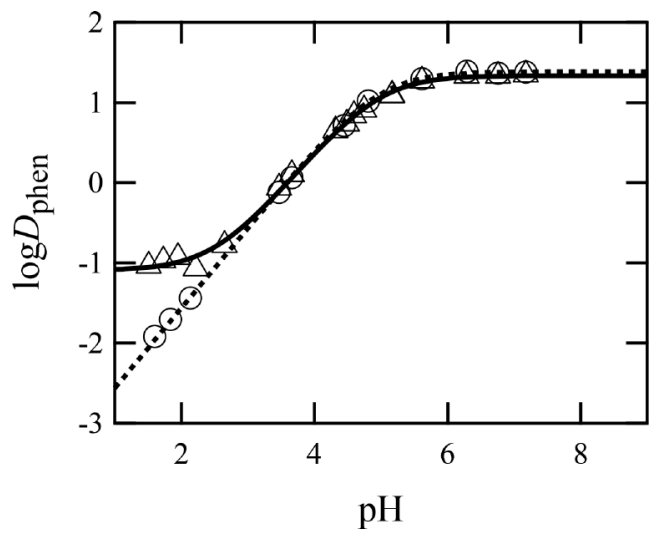

Fig. 4 Distribution ratio of phen as a function of $\mathrm{pH}$ in the aqueous phase. $1.0 \times 10^{-1} \mathrm{~mol} \mathrm{dm}^{-3} \mathrm{NaClO}_{4}(\triangle)$ or $1.0 \times 10^{-1} \mathrm{~mol} \mathrm{dm}^{-3} \mathrm{NaCl}$ $(\bigcirc)$ is used as a salt. Initial concentration of phen is $1.0 \times 10^{-3} \mathrm{~mol}$ $\mathrm{dm}^{3}$. The solid and dotted curves show the calculated values when using $\mathrm{NaClO}_{4}$ and $\mathrm{NaCl}$, respectively.

respectively. The calculated results (solid curve in Fig. 3) reproduced the experimental data well, and the value of $\mathrm{p} K_{\mathrm{a}, \mathrm{Hipt}}$ is consistent with the reported one (7.06).$^{18}$

\section{Determination of distribution constant of phen in $D C B$}

Figure 4 shows the distribution ratio $\left(D_{\text {phen }}\right)$ of phen between the aqueous and DCB phases as a function of the $\mathrm{pH}$. In the presence of $\mathrm{Cl}^{-}$, the distribution curve shows a typical distribution profile for a monoacidic base, where $\log D_{\text {phen }}$ is almost constant at a higher $\mathrm{pH}$ region, and follows a straight line having a slope of 1 at a lower $\mathrm{pH}$ region. On the other hand, in the presence of $\mathrm{ClO}_{4}^{-}, \log D_{\text {phen }}$ at a lower $\mathrm{pH}$ region $(\mathrm{pH}<3)$ is larger than that in the presence of $\mathrm{Cl}^{-}$, and seems to approach a constant value. The distribution behavior can be explained by the ion-pair extraction of protonated $\mathrm{Hphen}^{+}$with $\mathrm{ClO}_{4}^{-}$, and $D_{\text {phen }}$ in the presence of $\mathrm{Cl}^{-}$and $\mathrm{ClO}_{4}^{-}$is expressed as follows:

$$
\begin{aligned}
D_{\mathrm{Phen}, \mathrm{Cl}^{-}} & =\frac{K_{\mathrm{D}, \text { phen }}}{1+\left(\left[\mathrm{H}^{+}\right] / K_{\mathrm{a}, \mathrm{Hphen}^{+}}\right)}, \\
D_{\mathrm{Phen,ClO}_{+}^{-}} & =\frac{K_{1, \text { phen }}\left[\mathrm{ClO}_{4}^{-}\right]\left[\mathrm{H}^{+}\right]+K_{\mathrm{D}, \text { phen }} K_{\mathrm{a}, \mathrm{Hphen}^{+}}}{K_{\mathrm{a}, \mathrm{Hphen}^{+}}+\left[\mathrm{H}^{+}\right]},
\end{aligned}
$$

where $K_{\mathrm{D}, \text { phen }}, K_{\mathrm{a}, \mathrm{Hphen}}$, and $K_{\mathrm{I} \text {,phen }}$ are the distribution constant of phen, the acid dissociation constant of $\mathrm{Hphen}^{+}$, and ion-pair extraction constant of $\mathrm{Hphen}^{+}$with $\mathrm{ClO}_{4}^{-}$, respectively, and are given by

$$
\begin{aligned}
& K_{\mathrm{D}, \text { phen }}=\frac{[\mathrm{phen}]_{\mathrm{org}}}{[\mathrm{phen}]}, \\
& K_{\mathrm{a}, \mathrm{Hphen}^{+}}=\frac{\left[\mathrm{H}^{+}\right][\mathrm{phen}]}{\left[\mathrm{Hphen}^{+}\right]}, \\
& K_{\mathrm{I}, \text { phen }}=\frac{\left[\mathrm{Hphen}^{+} \cdot \mathrm{ClO}_{4}^{-}\right]_{\mathrm{org}}}{\left[\mathrm{Hphen}^{+}\right]\left[\mathrm{ClO}_{4}^{-}\right]} .
\end{aligned}
$$

The two $\log D_{\text {phen }}$ curves in Fig. 4 were fitted by a nonlinear least-squares method based on Eq. (6) or (7). The values of $\log K_{\mathrm{D} \text {,phen }}, \mathrm{p} K_{\mathrm{a}, \mathrm{Hphen}}$, and $\log K_{\mathrm{I}, \text { phen }}$ determined are given in Table 1. The calculated results (solid curves in Fig. 4) reproduced the experimental data well, and the value of $\mathrm{p} K_{\mathrm{a}, \mathrm{Hphen}^{+}}$ is consistent with the reported one (4.94). ${ }^{19}$ 
Extraction equilibrium analysis of Ln(III) extraction with Hipt and phen

The distribution ratio of $\mathrm{Ln}$ (III) in the Hipt-phen- $\mathrm{ClO}_{4}{ }^{-}$-DCB system was determined at various $\mathrm{pH}$ values and concentrations of Hipt and phen. In Fig. 5(a), the logarithmic distribution ratio $(\log D)$ for $\mathrm{La}(\mathrm{III})$ at a fixed concentration of phen in DCB phase ([phen $]_{\text {org }}$ ) is plotted as a function of the logarithmic concentration of $\mathrm{ipt}^{-}$in the aqueous phase, [ipt- ${ }^{-}$, that was given by

$$
\left[\mathrm{ipt}^{-}\right]=\frac{c_{\mathrm{Hipt}}}{\left(K_{\mathrm{D}, \mathrm{Hipt}}+1\right)\left[\mathrm{H}^{+}\right] / K_{\mathrm{a}, \mathrm{Hipt}}+1} .
$$

Where $c_{\text {Hipt }}$ is the initial concentration of Hipt. From the slope of the $\log D-\log \left[\mathrm{ipt}^{-}\right]$plot, $\mathrm{La}(\mathrm{III})$ is found to be coordinated by the two ipt $^{-}$molecules, suggesting that $\mathrm{La}$ (III) forms a monocationic complex and is extracted as an ion-pair with $\mathrm{ClO}_{4}{ }^{-}$into DCB. In Fig. 5(b), $\log D$ at a fixed [ipt $\left.{ }^{-}\right]$is plotted as a function of [phen $]_{\text {org }}$, which is expressed as follows:

$$
\text { [phen }]_{\text {org }}=\frac{c_{\text {phen }}}{\left(1+\frac{1}{K_{\mathrm{D}, \text { phen }}}\left(1+\frac{\left[\mathrm{H}^{+}\right]}{K_{\mathrm{a}, \text { Hphen }^{+}}}\left(1+K_{\mathrm{I}, \text { phen }}\left[\mathrm{ClO}_{4}^{-}\right]\right)\right)\right)},
$$

where $c_{\text {phen }}$ is the initial concentration of phen. The slope of the plot varies from one to two according to [phen $]_{\text {org }}$, indicating that the $\mathrm{La}$ (III) is extracted as the species coordinated by one phen molecule or as the one coordinated by two phen molecules competitively. The slopes of $\log D$-[ipt $]$ plots and $\log D$-[phen $]_{\text {org }}$ plots for $\mathrm{Eu}(\mathrm{III})$ and $\mathrm{Lu}(\mathrm{III})$ are shown in Fig. S2 (Supporting Information). From the slopes of these plots, two ipt $^{-}$molecules

Table 1 Equilibrium constants determined by the distribution experiments of phen between the aqueous and DCB phases at $25^{\circ} \mathrm{C}$

\begin{tabular}{cccc}
\hline \multicolumn{1}{c}{ Salt } & $\mathrm{p} K_{\mathrm{a}}$ & $\log K_{\mathrm{D}, \text { phen }}$ & $\log K_{\mathrm{I}, \text { phen }}$ \\
\hline $\mathrm{NaCl}$ & $4.95 \pm 0.02$ & $1.38 \pm 0.01$ & - \\
$\mathrm{NaClO}_{4}$ & $4.94 \pm 0.05$ & $1.33 \pm 0.03$ & $-0.10 \pm 0.03$ \\
\hline
\end{tabular}

and one or two phen molecules are found to be coordinated to $\mathrm{Eu}(\mathrm{III})$ and $\mathrm{Lu}(\mathrm{III})$, similar to $\mathrm{La}(\mathrm{III})$.

To clarify the variation of the extracted species, all of the experimental distribution ratio data were analyzed according to the following extraction equilibrium. In this case, the extraction equilibrium and the extraction constants are expressed by

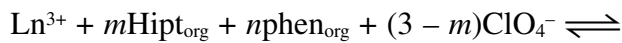

$$
\begin{aligned}
& \mathrm{Ln}(\mathrm{ipt})_{\mathrm{m}}(\text { phen })_{\mathrm{n}} \cdot\left(\mathrm{ClO}_{4}\right)_{3-\mathrm{m}, \mathrm{org}}+m \mathrm{H}^{+} \text {, } \\
& K_{\text {ex }, \mathrm{smn}}=\frac{\left[\mathrm{Ln}(\mathrm{ipt})_{\mathrm{m}}(\mathrm{phen})_{\mathrm{n}} \cdot\left(\mathrm{ClO}_{4}\right)_{3-\mathrm{m}}\right]_{\mathrm{org}}\left[\mathrm{H}^{+}\right]^{\mathrm{m}}}{\left[\mathrm{Ln}^{3+}\right][\mathrm{Hipt}]_{\mathrm{org}}^{\mathrm{m}}[\mathrm{phen}]_{\mathrm{org}}^{\mathrm{n}}\left[\mathrm{ClO}_{4}^{-}\right]^{3-\mathrm{m}}} .
\end{aligned}
$$

From Eq. (14), the distribution ratio of $\operatorname{Ln}(\mathrm{III})$ between the two phases is expressed as follows:

$$
\begin{aligned}
D & =\frac{\sum\left[\mathrm{Ln}(\mathrm{ipt})_{\mathrm{m}}(\mathrm{phen})_{\mathrm{n}} \cdot\left(\mathrm{ClO}_{4}\right)_{3-\mathrm{m}}\right]_{\mathrm{org}}}{\left[\mathrm{Ln}^{3+}\right]+\left[\mathrm{Ln}(\mathrm{ipt})^{2+}\right]} \\
& =\frac{1}{\left(1+\beta_{1}\left[\mathrm{ipt}^{-}\right]\right)}\left(\sum_{\mathrm{m}} \sum_{\mathrm{n}} \frac{\left[\mathrm{ipt}^{-}\right]^{\mathrm{m}}[\mathrm{phen}]_{\mathrm{org}}^{\mathrm{n}}\left[\mathrm{ClO}_{4}^{-}\right]^{3-\mathrm{m}} K_{\mathrm{D}, \mathrm{Hipt}}^{\mathrm{m}} K_{\mathrm{ex}, \mathrm{smn}}}{K_{\mathrm{a}, \mathrm{Hipt}}^{\mathrm{m}}}\right)
\end{aligned}
$$

where $\beta_{1}$ represent the formation constant of a $1: 1$ chelate $\left(\operatorname{Ln}(\mathrm{ipt})^{2+}\right)$ in the aqueous phase, and the constant for each $\mathrm{Ln}$ (III) used in this study is shown in Table 2. ${ }^{15}$ The existence of other chelate complexes such as $1: 2$ and 1:3 complexes is assumed to be negligible under the given conditions, as reported previously. ${ }^{15-17}$ The 3-dimensional data of $\log D-\log \left[\mathrm{ipt}^{-}\right]$ $\log [\text { phen }]_{\text {org }}$, shown as the 2D color plot in Fig. 5(c), Fig. S2(c), and Fig. S2(f) were fitted with a nonlinear least-squares method based on Eq. (15), and the extraction constants for the respective
Table 2 Extraction constants of $\mathrm{Ln}(\mathrm{III})$ in the Hipt-phen- $\mathrm{ClO}_{4}^{-}$DCB system $\left(K_{\text {ex, s21 }}\right.$ and $\left.K_{\text {ex,s22 }}\right)$ and the formation constants of $\mathrm{Ln}$ $(\text { ipt })^{2+}$ in the aqueous phase at $25^{\circ} \mathrm{C}$

\begin{tabular}{lrcc}
\hline $\operatorname{Ln}(\mathrm{III})$ & \multicolumn{1}{c}{$\log K_{\text {ex,s21 }}$} & $\log K_{\mathrm{ex}, \mathrm{s} 22}$ & $\log \beta_{1}$ \\
\hline $\mathrm{La}(\mathrm{III})$ & $-1.49 \pm 0.04$ & $1.43 \pm 0.05$ & $5.94^{15}$ \\
$\mathrm{Eu}(\mathrm{III})$ & $1.92 \pm 0.04$ & $5.15 \pm 0.07$ & $7.04^{15}$ \\
$\mathrm{Lu}(\mathrm{III})$ & $3.86 \pm 0.04$ & $7.86 \pm 0.03$ & $8.10^{15}$
\end{tabular}

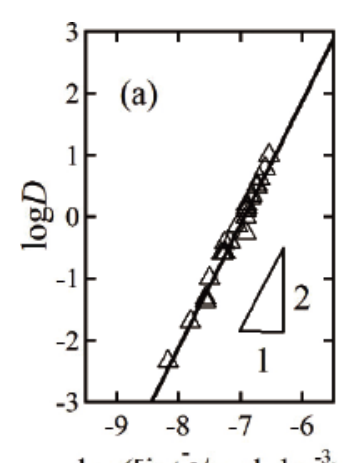

$\log \left(\left[\mathrm{ipt}^{-}\right] / \mathrm{mol} \mathrm{dm}^{-3}\right)$
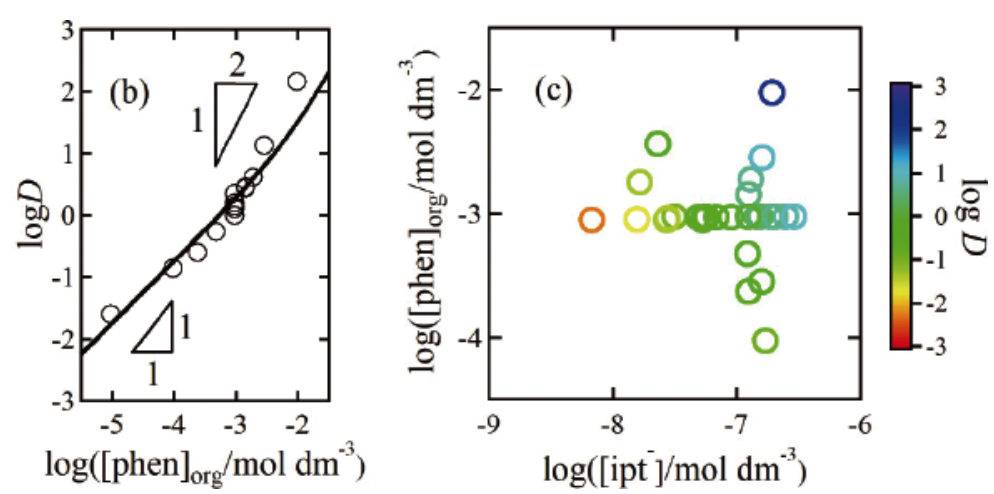

Fig. 5 Distribution ratio $(D)$ of $\mathrm{La}(\mathrm{III})$ as a function of the concentration of ipt ${ }^{-}$in the aqueous phase ([ipt $\left.\left.{ }^{-}\right]\right)$and/or that of phen in the DCB phase ([phen $\left.]_{\text {org }}\right)$. Panels (a), (b), and (c) represent a $\log D_{-}$ $\log \left[\mathrm{ipt}^{-}\right]$plot at $\log [\mathrm{phen}]_{\text {org }}=-3.02$, a $\log D-\log [\mathrm{phen}]_{\text {org }}$ plot at $\log \left[\mathrm{ipt}^{-}\right]=-6.90$, and a $2 \mathrm{D}$ color plot of $\log D$ as a function of $\log \left[\mathrm{ipt}^{-}\right]$and $\log [\mathrm{phen}]_{\text {org }}$, respectively. The solid curves in panels (a) and (b) show the values calculated from Eq. (15) using the constants in Table 2. Initial concentrations of $\mathrm{La}(\mathrm{III})$, Hipt, phen, and $\mathrm{NaClO}_{4}$ are $1.0 \times 10^{-5} \mathrm{~mol} \mathrm{dm}^{-3}, 2.5 \times 10^{-4}-4.0 \times 10^{-3} \mathrm{~mol} \mathrm{dm}^{-3}, 1.0 \times 10^{-5}-$ $1.0 \times 10^{-2} \mathrm{~mol} \mathrm{dm}^{-3}$, and $1.0 \times 10^{-1} \mathrm{~mol} \mathrm{dm}^{-3}$, respectively. $\mathrm{pH} 4.76-6.10$. 

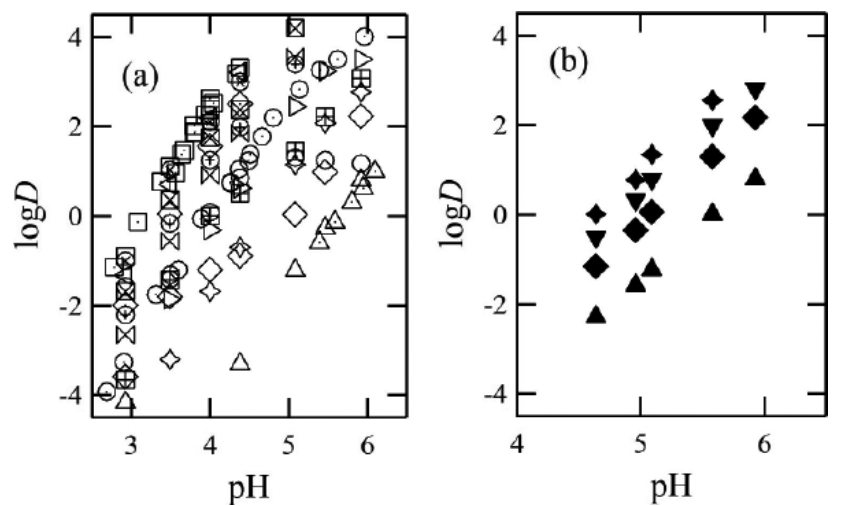

Fig. 6 Plots of $\log D-\mathrm{pH}$ for simultaneous extraction of (a) all lanthanoids except $\mathrm{Pm}$ (III) and (b) lighter lanthanoids (La(III) to $\mathrm{Nd}(\mathrm{III})$ ) in the Hipt-phen-ClO $4_{4}^{-}$-DCB system. In panel (b), ascorbic acid was added to reduce $\mathrm{Ce}(\mathrm{IV})$. Initial concentrations of $\mathrm{Ln}(\mathrm{III})$, Hipt, and phen are $1.0 \times 10^{-6} \mathrm{~mol} \mathrm{dm}^{-3}, 1.0 \times 10^{-3} \mathrm{~mol} \mathrm{dm}^{-3}$, and $1.0 \times 10^{-3} \mathrm{~mol} \mathrm{dm}^{-3}$, respectively. $\triangle, \mathrm{La} ; \diamond, \mathrm{Ce} ; \nabla, \mathrm{Pr} ; \diamond, \mathrm{Nd} ; \triangleright, \mathrm{Sm}$; $\odot, \mathrm{Eu} ; \boxplus, \mathrm{Gd} ; \bowtie, \mathrm{Tb} ; \oplus, \mathrm{Dy} ; \diamond, \mathrm{Ho} ; \otimes, \mathrm{Er} ; \triangleleft, \mathrm{Tm} ; \otimes, \mathrm{Yb} ; \bullet, \mathrm{Lu} ; \triangle$, La alone; $\bigcirc$, Eu alone; $\square$, Lu alone; $\mathbf{\Lambda}, \mathrm{La} ; \bullet, \mathrm{Ce} ; \boldsymbol{\nabla}, \mathrm{Pr} ; \bullet, \mathrm{Nd}$.

extracted species were determined. The extracted species are found to be $\mathrm{Ln}(\mathrm{ipt})_{2}$ phen $\cdot \mathrm{ClO}_{4}$ and $\mathrm{Ln}(\mathrm{ipt})_{2}$ (phen $)_{2} \cdot \mathrm{ClO}_{4}$, and their extraction constants obtained are given in Table 2 . The extraction phases were also analyzed by ESI-MS. The mass spectra for $\mathrm{Eu}(\mathrm{III})$ and $\mathrm{Lu}(\mathrm{III})$ show the peaks assigned as Ln(ipt $)_{2}$ phen $^{+}$and Ln(ipt) $)_{2}$ (phen $)_{2}{ }^{+}$(shown in Fig. S3 (Supporting Information)). Thus, the above assignment for the extracted species seems to be reasonable, although it is possible that the ESI process influences the composition of the extracted species, e.g. the mass spectrum for $\mathrm{La}$ (III) shows the prominent peak assigned as $\operatorname{Ln}(\mathrm{ipt})_{2}(\mathrm{phen})_{3}{ }^{+}$, whereas the $\operatorname{Ln}(\mathrm{III})$ species coordinated by three phen molecules are not found predominantly in the extraction data. In the presence of $\mathrm{NaCl}$ as a salt instead of $\mathrm{NaClO}_{4}$ (Hipt-phen-Cl--DCB system), the extracted species for $\mathrm{Eu}(\mathrm{III})$ and their extraction constants were determined by the same analysis for the data given in Fig. S4 (the detail is shown in Supporting Information). As a result, a neutral adduct complex, $\operatorname{Ln}(\mathrm{ipt})_{3}$ phen, was found to be extracted, and the value of $\log K_{\mathrm{ex}, 531}$ was -0.81 . Therefore, the ion-pair extraction of $\mathrm{Ln}$ (III) is a unique feature to the Hipt-phen- $\mathrm{ClO}_{4}^{-}$-DCB system and contributes to the superior extractability. The extraction

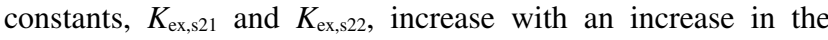
atomic number of the $\mathrm{Ln}(\mathrm{III})$, as reported in other extraction systems. $^{3-6}$ This trend can be explained not only by that ipt ${ }^{-}$, a basic ligand, interacts strongly with the heavier Ln(III) with a smaller ionic radius, but also by that phen forms a more stable adduct with heavier $\mathrm{Ln}(\mathrm{III})$ chelates.

Separation among lanthanoid ions using Hipt-phen- $\mathrm{ClO}_{4}^{-}-\mathrm{DCB}$ system

All lanthanoids, except for Pm(III), were extracted simultaneously using the Hipt-phen- $\mathrm{ClO}_{4}^{-}$-DCB system for the mutual separation of different lanthanoids. The distribution ratio of each $\operatorname{Ln}(\mathrm{III})$ is shown in Fig. 6(a). The $\log D$ data for the $\mathrm{La}(\mathrm{III}), \mathrm{Eu}(\mathrm{III})$, and $\mathrm{Lu}(\mathrm{III})$ in the figure is consistent with those shown in Fig. 2, where $\mathrm{La}(\mathrm{III}), \mathrm{Eu}(\mathrm{III})$, and $\mathrm{Lu}(\mathrm{III})$ are extracted independently in the Hipt-phen- $\mathrm{ClO}_{4}{ }^{-}$-DCB system, indicating that co-extraction of $\operatorname{Ln}(\mathrm{III})$ is negligible in the present extraction system. The extraction behavior of $\mathrm{Ce}(\mathrm{III})$ seems to be extraordinary at a lower $\mathrm{pH}$ region, e.g. the $\log D$ is deviated from the straight line and the value is larger than those

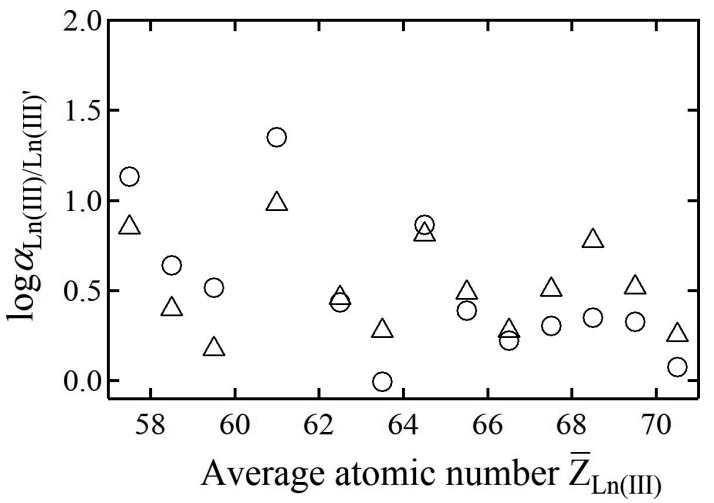

Fig. 7 Separation factors between adjacent lanthanoids across the $\mathrm{Ln}(\mathrm{III})$ series $\left(\alpha_{\mathrm{Ln}(\mathrm{III}) / \mathrm{Ln}(\mathrm{III})^{\prime}}\right)$ in the Hipt-phen- $\mathrm{ClO}_{4}{ }^{-}$-DCB system $(\mathrm{O})$ and those in the $\mathrm{PC}-88 \mathrm{~A}-\mathrm{HNO}_{3}$-decane system reported previously ${ }^{22}$ $(\triangle)$. Horizontal axis is the average of atomic numbers of the two lanthanoids to be compared. For $Z_{\mathrm{Ln}(\mathrm{III})}=61$, a separation factor between $\mathrm{Sm}(\mathrm{III})$ and $\mathrm{Nd}(\mathrm{III})(Z=61$ and 59$)$ was calculated.

of $\operatorname{Pr}(\mathrm{III})$ and $\mathrm{Nd}(\mathrm{III})$ with a larger atomic number. One plausible reason for this is that cerium is extracted partially as a tetravalent species, as reported previously. ${ }^{20}$ Thus, the extraordinary behavior for the cerium extraction was not found in the presence of ascorbic acid (Fig. 6(b)), which is capable of reducing $\mathrm{Ce}(\mathrm{IV})$ to $\mathrm{Ce}(\mathrm{III}){ }^{21}$

From the experimental distribution ratios, the separation factors between adjacent lanthanoids $\alpha_{\mathrm{Ln}(\mathrm{III}) / \mathrm{Ln}(\mathrm{III})^{\prime}}$ were calculated by $\alpha_{\mathrm{Ln}(\mathrm{III}) / \mathrm{Ln}(\mathrm{III})^{\prime}}=D_{\mathrm{Ln}(\mathrm{III})} / D_{\mathrm{Ln}(\mathrm{III})^{\prime}}$. Figure 7 gives the logarithmic values of $\alpha_{\mathrm{Ln}(\mathrm{III}) / \mathrm{Ln}(\mathrm{IIII})^{\prime}}$ under the following conditions, $\alpha_{\mathrm{Ce}(\mathrm{III}) / \mathrm{La}(\mathrm{III})}$ to $\alpha_{\mathrm{Nd}(\mathrm{III}) / \mathrm{Pr}(\mathrm{III})}$ at $\mathrm{pH} 4.64$ and $\alpha_{\mathrm{Sm} \text { (III)/Nd(III) }}$ to $\alpha_{\mathrm{Lu}(\mathrm{III}) / \mathrm{Yb}(\mathrm{III})}$ at $\mathrm{pH} 3.49$. The value of $\alpha_{\mathrm{Gd}(\mathrm{III}) / \mathrm{Eu}(\mathrm{III})}$ is found to be almost unity, indicating that the extractability of $\mathrm{Gd}(\mathrm{III})$ and $\mathrm{Eu}(\mathrm{III})$ are so similar that the two lanthanoids cannot be separated from each other. This behavior is known as a "Gadolinium break", which originates from a reduction of the coordination number from $\mathrm{Eu}$ (III) to Gd(III) (9 to 8). The values of $\alpha_{\mathrm{Ln}(\mathrm{III}) / \mathrm{Ln}(\mathrm{III})^{\prime}}$ for lighter lanthanoids in the present extraction system are higher than those when the lanthanoids are extracted from a nitric acid solution with 2-ethylhexyl phosphonic acid mono-2-ethylhexyl ester (PC-88A) in 1-decane (PC-88A-HNO ${ }_{3}$-decane system), which is used as an industrial extraction system, ${ }^{22}$ indicating that the present system has the potential to achieve superior efficiency of mutual separation between the lighter $\mathrm{Ln}(\mathrm{III})$.

The dependence of the separation efficiency on the extraction conditions, such as the concentrations of Hipt and phen, was examined based on the determined extraction constants. Figure 8 shows 3D plots of $\alpha_{\mathrm{Eu}(\mathrm{III}) / \mathrm{La} \text { (III) }}$ and $\alpha_{\mathrm{Lu}(\mathrm{III}) / \mathrm{Eu}(\mathrm{III})}$ depending on [ipt ${ }^{-}$and [phen $]_{\text {org }}$, which is calculated from the values of $K_{\text {ex,s21 }}$ and $K_{\text {ex,s22 }}$ as follows:

$$
\begin{aligned}
& \alpha_{\mathrm{Ln}(\mathrm{III}) / \mathrm{Ln}(\mathrm{III})^{\prime}}=D_{\mathrm{Ln}(\mathrm{III})} / D_{\mathrm{Ln}(\mathrm{III})^{\prime}} \\
& =\frac{\frac{1}{\left(1+\beta_{\mathrm{l}(\mathrm{Ln}(\mathrm{III}))}\left[\mathrm{ipt}^{-}\right]\right)} \sum_{\mathrm{n}=1,2} \frac{\left[\mathrm{ipt}^{-}\right][\mathrm{phen}]_{\mathrm{org}}^{\mathrm{n}}\left[\mathrm{ClO}_{4}^{-}\right] K_{\mathrm{D}, \mathrm{Hipt}}^{2} K_{\mathrm{ex}, \mathrm{s2n}(\mathrm{Ln}(\mathrm{III}))}}{K_{\mathrm{a}, \mathrm{Hipt}}^{2}}}{\frac{1}{\left(1+\beta_{1\left(\mathrm{Ln}(\mathrm{III})^{\prime}\right)}\left[\mathrm{ipt}^{-}\right]\right)} \sum_{\mathrm{n}=1,2} \frac{\left[\mathrm{ipt}^{-}\right][\mathrm{phen}]_{\mathrm{org}}^{\mathrm{n}}\left[\mathrm{ClO}_{4}^{-}\right] K_{\mathrm{D}, \mathrm{Hipt}}^{2} K_{\mathrm{ex}, \mathrm{s2n}\left(\mathrm{Ln}(\mathrm{III})^{\prime}\right)}}{K_{\mathrm{a}, \mathrm{Hipt}}^{2}}}
\end{aligned}
$$

The values of $\alpha_{\mathrm{Eu}(\mathrm{III}) / \mathrm{La}(\mathrm{III})}$ and $\alpha_{\mathrm{Lu}(\mathrm{III}) / \mathrm{Eu}(\mathrm{III})}, \quad$ determined experimentally also given in Fig. 8, are reproduced well by the calculation. For both $\alpha_{\mathrm{Eu}(\mathrm{III}) / \mathrm{La}(\mathrm{III})}$ and $\alpha_{\mathrm{Lu}(\mathrm{III} / \mathrm{Eu}(\mathrm{III})}$, the values are independent of $\left[\mathrm{ipt}^{-}\right]$, and increase with an increase in [phen] $]_{\text {org }}$. The variations of $\alpha_{\mathrm{Eu}(\mathrm{III}) / \mathrm{La} \text { (III) }}$ and $\alpha_{\mathrm{Lu}(\mathrm{III}) / \mathrm{Eu}(\mathrm{III})}$ to [phen] org are 

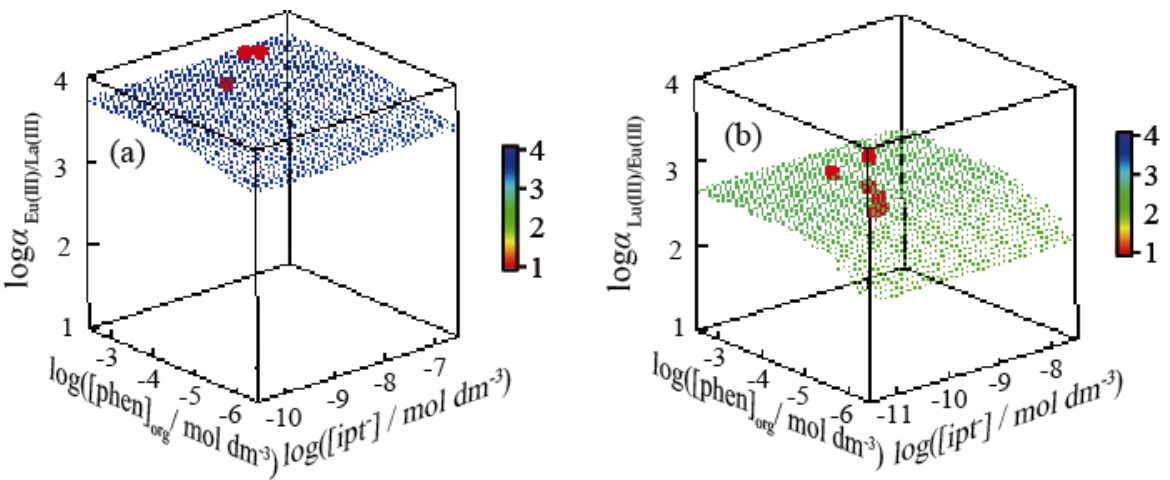

Fig. 8 Separation factors (a) between $\mathrm{Eu}(\mathrm{III})$ and $\mathrm{La}(\mathrm{III})$ and (b) between $\mathrm{Lu}(\mathrm{III})$ and $\mathrm{Eu}(\mathrm{III})$, calculated from the extraction constants determined. The circles represent the separation factors determined experimentally.

ascribed to the difference in the composition of the predominant adduct species: $\mathrm{Ln}(\mathrm{ipt})_{2}$ (phen $)_{2} \cdot \mathrm{ClO}_{4}$ is more dominant at high [phen] org, whereas $\mathrm{Ln}(\mathrm{ipt})_{2}(\mathrm{phen})_{2} \cdot \mathrm{ClO}_{4}$ is more dominant at a low [phen] $]_{\text {org. }}$. The deviation of $K_{\text {ex,s22 }}$ is slightly larger than that of $K_{\text {ex,s21 }}$. Therefore, phen as a neutral ligand not only enhances the extractability of $\mathrm{Ln}(\mathrm{III})$, but also improves the separation efficiency between different lanthanoids.

\section{Conclusions}

The synergistic extraction of $\operatorname{Ln}(\mathrm{III})$ with Hipt and phen in DCB was investigated, and the extracted species and their extraction constants were determined by a 3D equilibrium analysis. In the presence of $\mathrm{NaClO}_{4}$ as a salt, ion-pairs, such as and, are extracted into the DCB phase, in contrast to the extraction with Hipt alone, where polynuclear metal complexes are extracted or the extraction with $\mathrm{NaCl}$ as a salt where neutral adduct complexes are extracted. As a result of the simultaneous extractions of different lanthanoids in the Hipt-phen- $\mathrm{ClO}_{4}{ }^{-}$-DCB system, the separation factors for lighter lanthanoids are found to be larger than those in one of the industrial extraction system, indicating that the present extraction system has the potential to achieve a superior separation performance for lighter lanthanoids.

\section{Acknowledgements}

This study was supported by JSPS KAKENHI Grant No. 25620108 .

\section{Supporting Information}

$\log D$ plots at various metal concentration for $\mathrm{Eu}(\mathrm{III}), \log D$ plots of $\mathrm{Eu}(\mathrm{III})$ and $\mathrm{Lu}(\mathrm{III})$ in the Hipt-phen- $\mathrm{ClO}_{4}{ }^{-}$-DCB system, ESI mass spectra of the extracted species in the Hiptphen- $\mathrm{ClO}_{4}^{-}$-DCB system, $\log \mathrm{D}$ plots of $\mathrm{Eu}$ (III) in the Hiptphen- $\mathrm{Cl}^{-}$-DCB system. This material is available free of charge on the Web at http://www.jsac.or.jp/analsci/.

\section{References}

1. T. V. Healy, J. Inorg. Nucl. Chem., 1961, 19, 314.

2. T. Sekine and D. Dyrssen, J. Inorg. Nucl. Chem., 1967, 29, 1481.

3. E. F. Kassierer and A. S. Kertes, J. Inorg. Nucl. Chem., 1972, 34, 3221.

4. E. F. Kassierer and A. S. Kertes, Inorg. Chem., 1972, 11, 2108.

5. S. Nakamura and N. Suzuki, Polyhedron, 1988, 7, 155.

6. S. Nakamura and N. Suzuki, Bull. Chem. Soc. Jpn., 1993, 66, 98.

7. Y. Kitatsuji, Y. Meguro, Z. Yoshida, T. Yamamoto, and K. Nishizawa, Solvent Extr. Ion Exch., 1995, 13, 289.

8. N. Hirayama, H. Okamura, K. Kidani, and H. Imura, Anal. Sci., 2008, 24, 697.

9. M. Atanassova, Solvent Extr. Ion Exch., 2009, 27, 159.

10. H. Okamura, H. Takagi, T. Isomura, K. Morita, H. Nagatani, and H. Imura, Anal. Sci., 2014, 30, 323.

11. T. Hori, M. Kawashima, and H. Freiser, Sec. Sep. Tecnol., 1980, $15,861$.

12. E. Yamada and H. Freiser, Anal. Chem., 1981, 53, 2115.

13. O. Tochiyama and H. Freiser, Anal. Chim. Acta, 1981, 131, 233.

14. H. Imura and J. Sakurai, Japan Patent, 2010, 270359A.

15. Y. Higuchi, Y. Nishiyama, H. Nagatani, and H. Imura, Monatsh. fur. Chem., 2019, 150, 821.

16. J. Noro, Anal. Sci., 1998, 14, 1099.

17. J. Noro, Anal. Sci., 1999, 15, 1265.

18. T. Sekine and D. Dyrssen, Talanta, 1964, 11, 867.

19. K. Ishimori, H. Imura, and K. Ohashi, Anal. Chim. Acta, 2002, 454, 241.

20. S. Nakamura, Y. Surakitbanharn, and K. Akiba, Anal. Sci., 1989, 5, 739.

21. K. Tonosaki and M. Otomo, Bull. Chem. Soc. Jpn., 1962, $35,1683$.

22. G. Adachi, "Science of Rare Earths", 1999, Kagakudoujin, Kyoto, 194. 